\title{
Innovative Technologies for Natural Gas Utilization in Power Generation
}

\author{
Victor M. Maslennikov, Vyacheslav M. Batenin, \\ Yury A. Vyskubenko and Victor Ja. Shterenberg \\ Joint Institute for High Temperatures of the Russian Academy of Sciences, \\ Russian Federation
}

\section{Introduction}

Numerous publications are dedicated to the development of traditional power engineering and to the possibility for essentially new power generation methods to appear. But if we shell a try to make detailed analysis of this issue for near perspective, the imagination has to be limited substantially. First of all, these limitations are connected with the great scale of the problem.

Appearance of a new technology in field of power generation, apparently may be considered as real, only when the first demonstration plant will comes into service or when the way of the transition from ideas and experiments to creation of the new plant is clear, together with needed time and resources. According to the progress in the last 40 years, a few of the principled new power production technologies have been realized [1,3]. Here, gas-turbine and combined cycle steam-gas technologies are the best examples. For the most parts progress consists of step-by-step enhancement and parameter increase, that had resulted in the qualitative growth of technical and economic indicators. In general, power engineering remains a very conservative field.

The second boundary condition of the origination of a new power production technology is the presence of the necessary volume of primary resources. However, the excess some of these resources can slow down the development of new technologies, based on the other primary resources.

Finally, with the start of XXI century, power generation development is more and more coordinated by the world community, which connects the increase of fossil based power production with the possible global climate change.

In respect to Russia, these boundary conditions are added by internal problems of new economic structure formation, which take rather long period of solution, according to the experience of the last two decades.

The estimations of organic fuel resources give their inevitable depletion in the foreseeable future. However, the exact figures are under permanent correction. Crude oil resources, apparently, are minimal even with taking into account the volumes which are difficult to 
extract and the development of new methods of extractions. Concerning natural gas, the estimations are more optimistic. The resources of natural gas assured and perspective for recovery grow (methane of coal beds and shale gas, for example). With respect to possibility of gas hydrates utilization, the reserves of gas seem to be practically unlimited for power production in the oncoming century.

The above mentioned is also true for the reserves of coal. Thereby, natural gas and coal are the most important primary energy resources.

With this, analyzing the perspectives of all power production technologies based on fossil fuels, it is worth taking into account the following:

- The problem of transportation is very actual because the gas and coal fields in most cases are distant from the areas of electric energy consumption;

- Transformation efficiency increase connected not only with fuel saving, but also with the reduction of greenhouse gases emission;

- Mono-production of electric energy does not correspond with long-term energy strategy;

- Even at keeping the present level of electric power production in Russia up to 2030, to compensate the retirement of power of thermal power plants only, it is necessary to put new $7-8$ million of $\mathrm{Kw} /$ year in operation, where $4-5$ million of $\mathrm{Kw} /$ year using natural gas, mainly at high capacity steam-gas plants.

Taking into account that not less than 10 years are to pass from draft technical proposal of new power production technology to the creation of big-scale demonstration plant, the problem of advance thermal efficiency at power production, natural gas first of all, should be solved in two directions:

1. By the upgrade at existing power plants, as a first stage;

2. The creation of principally new high efficient ecologically clean power units to replace the worked-out power units and for further development of fossil fuel power production.

Below is the description of several new technologies for natural gas utilization developed in Joint Institute for High Temperatures of Russian Academy of Sciences (JIHT RAS) in both areas.

\section{Efficiency increase of existing power production facilities}

\subsection{Repowering of the existing water-heating boiler}

Repowering of the existing gas fueled water-heating boiler by adding of gas-turbine units with its outlet to the boiler combustor for the first time was proposed by group of JIHT RAS specialists headed by Academician Mikhail Styrikovich in the 80th. At present this proposal is recognized and accepted for implementation, however big discrepancy exists in the reading of its technical essence, up to absurd (creation of gas-turbine units with exhaustheat boilers at boiler facilities). The essence of the proposal is in the following: products of combustion from gas-turbine unit, containing $17 \%$ of free oxygen are fed to boiler combustor (Fig.1). 


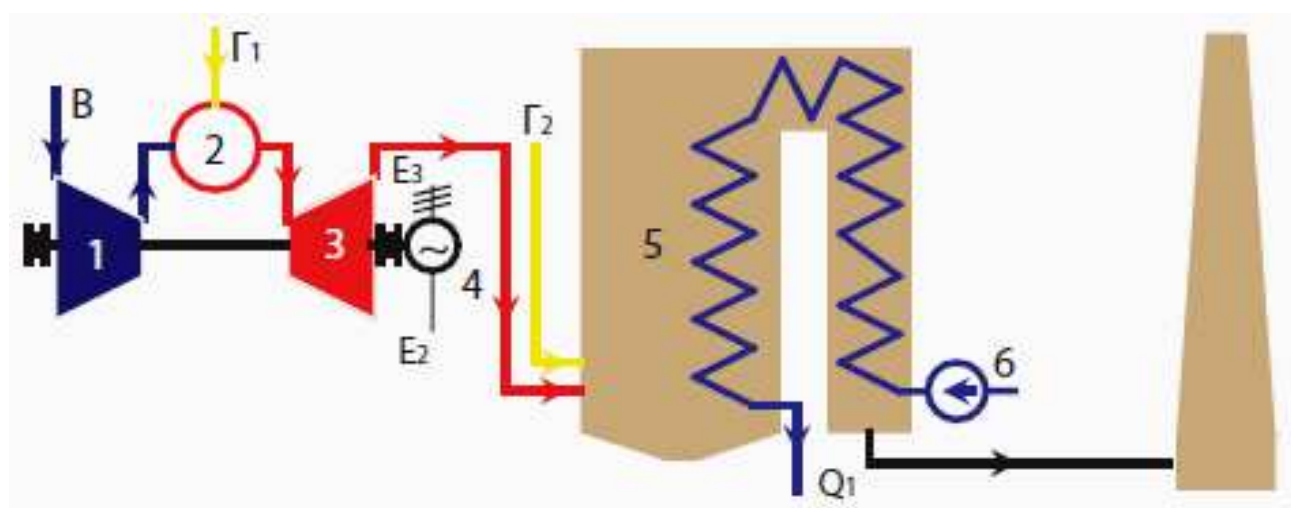

B - air, $\Gamma 1$ - gas to GT combustor, Г2 - gas to boiler, 1 - compressor, 2 - combustion chamber, 3 - gas turbine, 4 - generator, 5 - boiler, 6 - feed pump.

Fig. 1. Water boiler with gas-turbine buildup.

With this, at minimal thermal load regime $(20 \%)$ the heat is generated due to the cooling of the gas turbine unit products of combustion. At the increase of thermal load (up to nominal), additional fuel is after-burned in the boiler in the flow of products of combustion due to free oxygen combustion. With this, the efficiency of electric power production changes from $60 \%$ (summer regime) to $90 \%$ (winter regime). The efficiency is defined as:

$$
\eta_{e}=\frac{N_{e}}{H_{T}-\frac{Q_{m}}{\eta_{b}}}
$$

Water heating boilers of $100 \mathrm{Gcal} / \mathrm{h}$ capacity could be built-up by gas-turbine units of 16-20 MW (defined by the products of combustion flowrate). Only in Moscow at district heating units there are about 100 of such boilers.

The described technology has one peculiarity, namely, the gas flow rate to boiler combustor changes in a wide range at near constant flow rate of oxidant, represented by the gas-turbine products of combustion. This can be implemented by step-by-step some burners switch off or by the installation of special burners. The technology can be applied without additional research at test units and the cost of electricity generated is lower than at perspective steamgas plants.

\subsection{Repowering of the existing gas-fired steam turbine units}

There are some variants to retrofit the steam turbine units with using gas turbines. A few obstacles need to be overcome for these possibilities to be namely: 
1. the extent, to which the equipment of the power plant to be retrofitted is worn out, needs to be taken into consideration, so that its remaining service life would not differ too much from the service life of the newly installed equipment;

2. free space must be available for installing new equipment at the existing power plant;

3. it is necessary that the newly installed equipment should not bring about a substantial reduction in the capacity and efficiency of the existing basic power-generating equipment; and

4. the new process scheme should not result in the loss of reliability of the object being retrofitted; in the worst case, it should not increase the environmental impact on the region, while in the best case it should considerably relieve this impact.

The technical offer made by OIVTAN was aimed at solving this actual problem and involved the retrofitting of existing, relatively new steam turbine units by way of integrating gas turbines into these units and employing an original technology referred to as "partial oxidation" [2], [4], [5]. This technology essentially consists in that the natural gas, utilized by the steam-turbine unit, is preconverted in the combustors of the gas-turbine unit to carbon monoxide and hydrogen, and the resultant fuel gas expands in the gas turbine and then burned in the boiler furnace.

\subsubsection{List of the units under consideration}

The investigation, presented in this chapter, deals with a comparative feasibility study of the most representative alternative options. The main items under comparison are:

- thermal efficiency additional power production,

- relative cost of electricity in base mode operation.

Five alternative options have been studied:

1. A conventional $315 \mathrm{MW}$ condensing steam-turbine unit fired with gas and fuel oil, for the steam parameters of $24 \mathrm{MPa}$ and $540 / 540 \mathrm{oC}$. (It was used as a standard for comparison).

2. A $150 \mathrm{MW}$ binary-cycle steam-gas unit (SGU) incorporating two W251B12 gas-turbine units by Westinghouse and a $51 \mathrm{MW}$ steam turbine.

3. Gas-turbine topping with partial oxidation process.

a. 7 variants with Aircraft Engines.

b. 4 variants with Heavy-duty GTU.

4. Topping with dumping of GTU gas into the boiler furnace (Hot-Windbox).

a. 4 variants with Aircraft Engines.

b. 2 variants with Heavy-duty GTU.

5. Topping with GTU combined with STU in a single steam-generating circuit.

\section{Standard steam-turbine unit}

Units of this type were commissioned widely since the 1970s. Following the period of debugging, they have exhibited high reliability and efficiency and are at present employed most extensively in the energy systems of Russia and republics of the former USSR. The present-day characteristics of this unit are listed in the following table 1. 


\begin{tabular}{|l|l|}
\hline Generator power, MW & 317.9 \\
Steam parameters: & \\
-At turbine inlet & \\
Flow rate, $\mathrm{kg} / \mathrm{s}$ & 276.7 \\
Pressure, $\mathrm{kg} / \mathrm{cm}^{2}$ & 240.0 \\
Temperature, $\mathrm{oC}$ & 540.0 \\
-At reheater outlet & \\
Flow rate, $\mathrm{kg} / \mathrm{s}$ & 221.3 \\
Pressure, $\mathrm{kg} / \mathrm{cm}^{2}$ & 38.6 \\
Temperature, ${ }^{\circ}$ & 540.0 \\
-At condenser inlet & \\
Flow rate, $\mathrm{kg} / \mathrm{s}$ & 169.7 \\
Pressure, $\mathrm{kg} / \mathrm{cm}^{2}$ & 0.035 \\
3. Feedwater temperature, oC & 280.8 \\
4. Pressure in deaerator, kg/cm ${ }^{2}$ & 7.0 \\
5. Number of regenerative feedwater heaters & \\
- low pressure & 4 \\
- high pressure & 3 \\
6. Feedpump turbodrive power, MW & 11.9 \\
7. Specific heat consumption, KJ/KWh & 8055 \\
8. Efficiency of boiler, \% & 94.5 \\
9. Unit net efficiency, \% & 40.6 \\
\hline
\end{tabular}

Table 1. The main characteristics of standard steam-turbine unit.

\subsubsection{An existing aircraft engine used as a topping unit in partial oxidation scheme}

The schematic diagram is given in Fig. 2.

The existing engine in this particular case is used as a "gas generator". The combustion products containing up to $17 \%$ free oxygen are passed from the gas turbine exhaust to a special converter (11), where natural gas is fed in excess.

In the converter (11), natural gas at a temperature of about $1100 \mathrm{oC}$ (possibly in the presence of a catalyst), is subjected to partial oxidation to hydrogen and carbon monoxide. The products of partial oxidation are expanded in the power gas turbine (3) and discharged as fuel to the upper tiers of the steam boiler. (The lower tier of the boiler may be operated on the former fuel).

Steam extracted from the STU exhaust to the GTU can be used in the topping for the following purposes:

- Cooling the power gas turbine blades;

- Increasing power output of the gas turbine (being fed into the combustion chamber of the aircraft engine (2);

- Decreasing the soot formation (being fed into the converter(11).

In order to enhance the efficiency some part of the combustion products may by-pass and fed to the additionally installed boiler feedwater preheaters. In doing so, the steam extracted from the steam turbine exhaust for feedwater preheating is changed to optimize thermal circuit.

The main characteristics of two variants of this unit are listed in the table 2. 


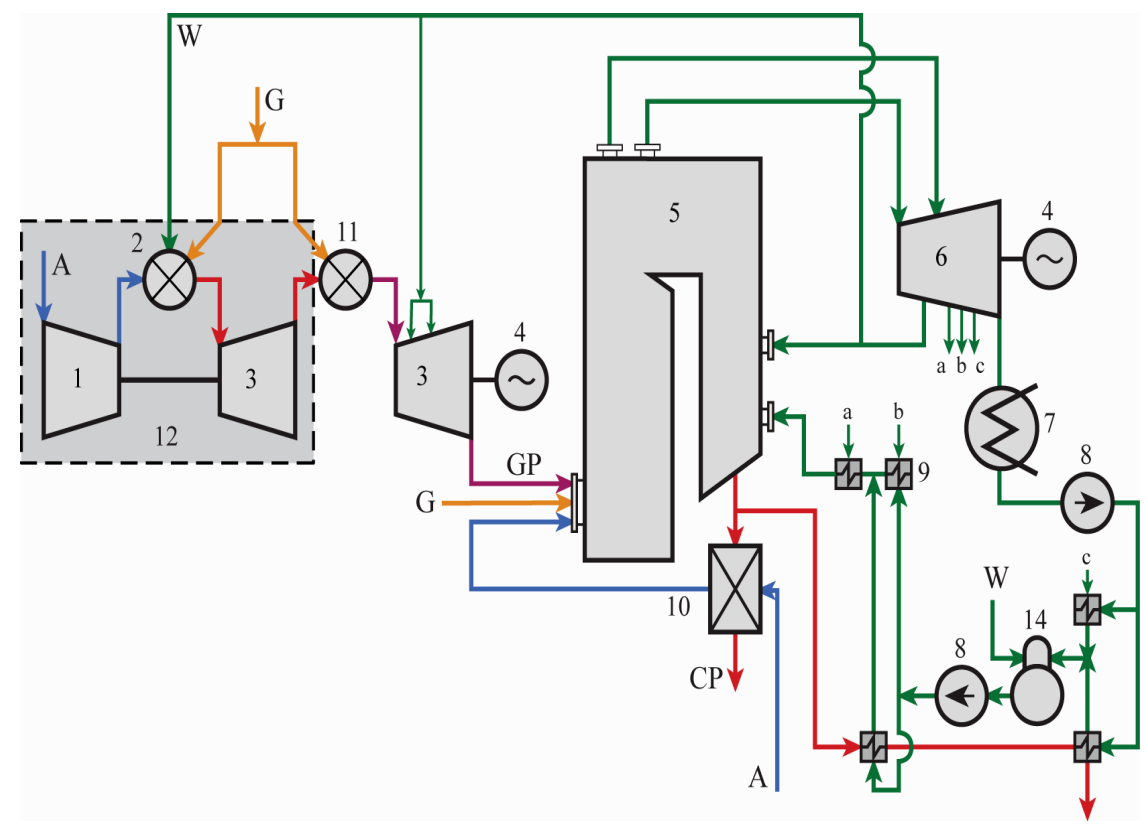

1 - compressor, 2 - combustion chamber, 3 - gas turbine, 4 - electric generator, 5 - steam boiler, 6 -steam turbine, 7 - steam condenser, 8 - feed pump, 9 - steam regeneration, 10 - air heater, 11 - partial oxidation chamber, 12 - gas generator (AGTE block), 13 - deaerator.

A -air, G -natural gas, CP - combustion products, GP - natural gas conversion products, $\mathrm{W}$ - water, steam

Fig. 2. Repowering by addition of topping SGU based on aircraft gas turbine with using partial oxidation.

\begin{tabular}{|c|c|c|c|c|}
\hline Steam injection into GTU, kg/s & \multicolumn{2}{|c|}{$\mathbf{0 . 0}$} & \multicolumn{2}{c|}{$\mathbf{1 9 . 0}$} \\
\hline MODES & 1 & 2 & 1 & 2 \\
\hline Main characteristics & 38.2 & 38.2 & 74.5 & 74.5 \\
\hline 1. GTU total power, MW & 7.78 & 7.35 & 8.95 & 8.37 \\
2. Additional gas flow to the boiler, kg/s & 48.1 & 46.7 & 53.2 & 51.5 \\
as \% of the total flow & & & & \\
3. Efficiency of boiler, \% & 91.9 & 91.7 & 89.9 & 89.7 \\
- boiler per se & 94.2 & 94.1 & 93.4 & 93.3 \\
- system comprising boiler+gas regenerator & 320.4 & 311.1 & 300.4 & 288.8 \\
4. SGU total power, MW & 9.6 & 9.6 & 9.6 & 9.6 \\
5. Parasitics, MW & 41.1 & 31.8 & 57.4 & 45.9 \\
6. Additional useful power of the unit, MW & 16.18 & 15.76 & 16.83 & 16.25 \\
7. Total fuel consumption by the unit, kg/s & 69.0 & 82.6 & 62.5 & 72.8 \\
8. Efficiency of additional el. power production, \% & &
\end{tabular}

Mode 1 - With gas regeneration. Ne add = Nmax.

Mode 2 - With gas regeneration. Efficienci = Max.

Table 2. The main characteristics of existing Aircraft Engine used as a topping unit in partial oxidation scheme. 


\subsubsection{A gas turbine with discharge of combustion products into the boiler furnace for repowering}

This scheme (Fig. 3) is well established and it is mentioned here as alternative, the comparison being carried out for the same initial assumptions. In distinction from fig 1 addition topping gas turbine to steam generation block.

The combustion products containing up to $17 \%$ free oxygen are discharged to the boiler burners where they are used as an oxidizer of the additionally fed fuel. To control the boiler steam production rate, additional amounts of air and fuel are added to some burners.

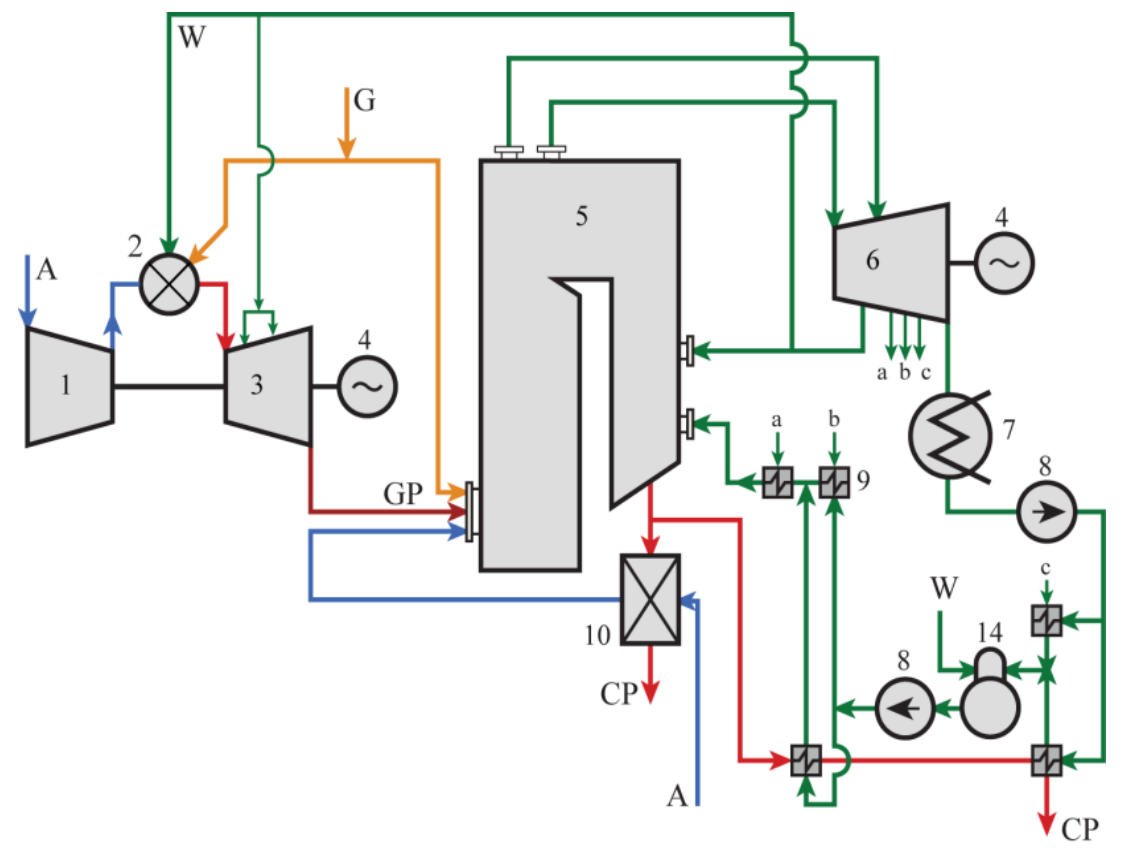

1 - compressor, 2 - combustion chamber, 3 - gas turbine, 4 - electric generator, 5 - steam boiler, 6 -steam turbine, 7 - steam condenser, 8 - feed pump, 9 - steam regeneration, 10 - air heater, 11 - deaerator. A -air, G -natural gas, CP - combustion products, GP - natural gas conversion products, $\mathrm{W}$ - water, steam

Fig. 3. Repowering by addition of topping SGU, based on Westinghouse GTU.

Since the air flow through the air preheater (10) decreases significantly, part of the combustion products is removed via a by-pass for heating feedwater in parallel with the steam regeneration system. The flow rate of the by-passed combustion products in this unit is much higher, then in units based on partial oxidation and, by consequence, a larger fraction of the steam regeneration is forced out, which leads either to a loss of efficiency, or to a decrease in power output of the steam turbine. In the comparative thermodynamic analysis given hereafter we shall analyze the effect of amount of the combustion products discharged into the boiler downstream of the GTU as well as changes in the steam regeneration system on the efficiency of additional production of electric power and change in the steam turbine power output. 


\subsubsection{GTU integrated with Steam Turbine Unit in a single steam generating circuit}

The schematic diagram of this option is given in Fig. 4. In this case the steam and the GTUs are operated to a large extent independently. However, the heat of combustion products downstream of the GTU is utilized for heating feedwater of the STU with partial forcing out the steam regeneration. Naturally, the efficiency of this scheme is lower than that of the above options, nevertheless it exhibits a number of important advantages:

- The problem of GTU location is simplified greatly.

- There is no need in revamping the major boiler components.

The main characteristics of both units are listed in the table 3.

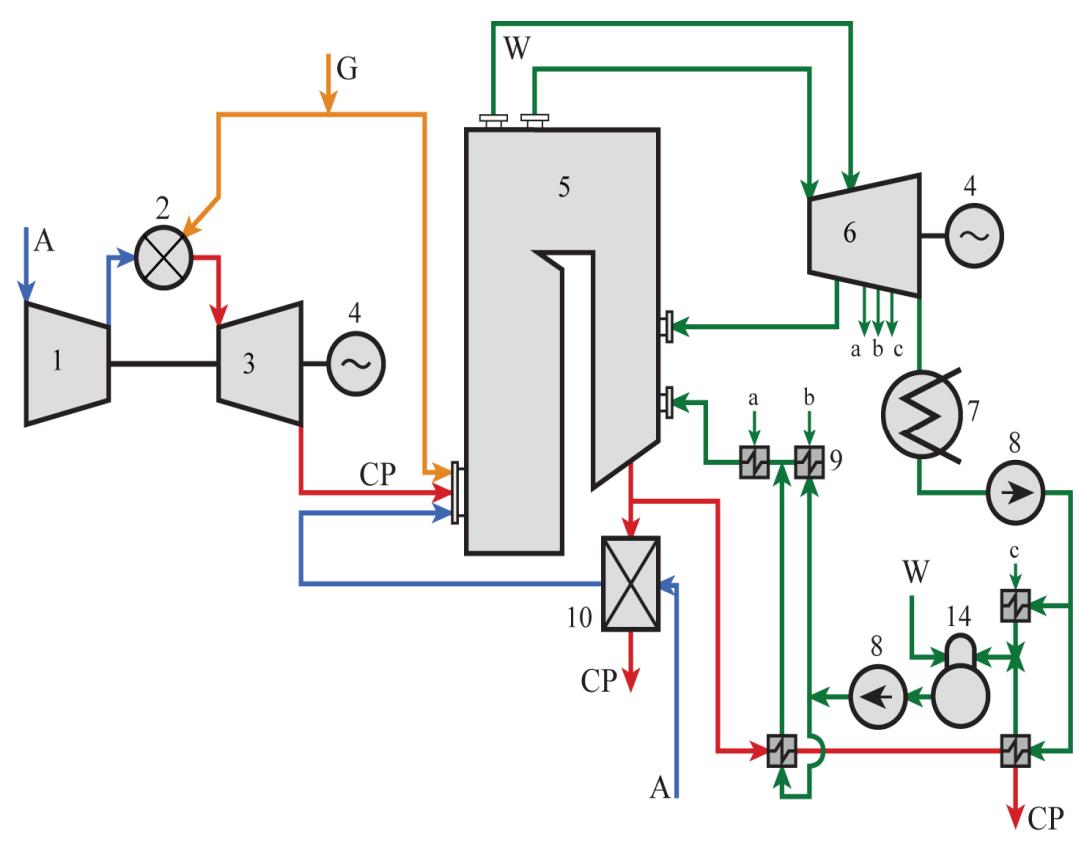

1 - compressor, 2 - combustion chamber, 3 - gas turbine, 4 - electric generator, 5 - steam boiler, 6 -steam turbine, 7 - steam condenser, 8 - feed pump, 9 - steam regeneration, 10 - air heater, 11 - deaerator. A -air, G -natural gas, CP - combustion products, GP - natural gas conversion products, $\mathrm{W}$ - water, steam

Fig. 4. Repowering by addition of GTU with combustion products exhaust to boiler. 


\begin{tabular}{|c|c|c|c|c|}
\hline \multirow{2}{*}{$\begin{array}{c}\text { Type of scheme } \\
\text { MODES }\end{array}$} & \multicolumn{2}{|c|}{$\begin{array}{c}\text { GTU with } \\
\text { discharge of comb. } \\
\text { products into the } \\
\text { boiler furnace }\end{array}$} & \multicolumn{2}{|c|}{$\begin{array}{l}\text { GTU integrated } \\
\text { with STU in a } \\
\text { single steam } \\
\text { generating circuit }\end{array}$} \\
\hline & 1 & 2 & 3 & 4 \\
\hline \multicolumn{5}{|l|}{ Main characteristics } \\
\hline 1. GTU total power, MW & 48.5 & 48.5 & 48.5 & 48.5 \\
\hline 2. Additional gas flow to the boiler, $\mathrm{kg} / \mathrm{s}$ & 14.0 & 12.6 & & \\
\hline As $\%$ of the total flow & 82.3 & 80.7 & & \\
\hline 3. Efficiency of boiler , \% & & & & \\
\hline - boiler per se & 88.9 & 87.4 & 94.5 & 94.4 \\
\hline - system comprising boiler+gas regenerator & 88.9 & 93.6 & & \\
\hline 4. STU total power, MW & 317.9 & 294.1 & 317.9 & 292.2 \\
\hline 5. Parasitics, MW & 10.1 & 10.1 & 10.4 & 10.4 \\
\hline 6. Additional useful power of the unit, MW & 48.5 & 24.7 & 48.2 & 22.5 \\
\hline 7. Total fuel consumption by the unit, $\mathrm{kg} / \mathrm{s}$ & 17.0 & 15.59 & 17.99 & 15.86 \\
\hline $\begin{array}{l}\text { 8. Efficiency of additional electric power } \\
\text { production, } \%\end{array}$ & 48.3 & 82.9 & 32.1 & 51.4 \\
\hline
\end{tabular}

Mode 1 - Without gas regeneration.

Mode 2 - With gas regeneration. Maximum heat use in gas regeneration system.

Mode 3 - Separate location of GTU and STU.

Mode 4 - GTU and STU are integrated in a single steam generating circuit.

Maximum heat use in gas regeneration system.

Table 3. The main characteristics of gas turbine with discharge of combustion products into boiler and gas turbine integrated with steam turbine in a single steam-generating circuit.

\subsubsection{Results of the thermodynamic analysis}

The following characteristics of the various schemes were used for comparison:

1. The additional useful power output of the steam-gas unit, SGU, (Ne add, MW),

2. Efficiency of Generation of the Additional Electric Power (Effadd).

$$
E f f_{a d}=\left(N_{S G U}-N_{S T U}\right) /\left(\sum g_{i *} Q_{i S G U}-\Sigma g_{i *} Q_{i S T U}\right)
$$

When a topping gas turbine unit is added to the STU quite natural desire is to introduce minimum changes into the flowsheet of the STU, and to retain the possibility of independent operation of the STU in case of shut-down of the GTU.

The efficiency of such repowering depends to a large extent on how successfully the following problems will be solved:

- Compatibility of the two units in flow rates of the working fluid, i.e. the possibility of passing a new volume of gases through the STU boiler so that no changes occur in the boiler working surfaces temperatures and the basic parameters of the boiler. In connection with the fact that the suggested Partial Oxidation Technology is of notably specific nature, in the calculation that will follow the " $\mathrm{Xf}$ " parameter will be introduced, equal to the ratio of fuel flow to the topping unit to the nominal fuel flow to the STU. 
- $\quad$ Any one of the topping GTU causes reduction of air flow through the regenerative air heater (RAH), and by consequence additional heat losses with the flue gases. To make up for these losses some part of the flue gases upstream of the RAH may be used for heating feedwater in a special heat exchanger with corresponding forcing out the steam regeneration.

- In the topping GTU using partial oxidation the gas turbines cannot use air as coolant due to both explosion danger and cooling efficiency. Therefore, in all calculations steam extracted from the steam turbine was used for this purpose. The cooling steam flow was determined to be such as to maintain the same temperature level of the components being cooled.

When optimizing the technological scheme in certain cases it is advisable to feed additional extracted steam to the GTU; in doing so the GTU power is appreciably increased. Although the efficiency of additional electric power production in this case may be lowered the total fuel savings in the repowered unit may be larger.

In this work the amount of steam injected into the gas turbine varies as an independent variable. The diagram in Fig. 5 illustrate the effect of using various schemes of gas regenerative heating of feedwater and also different amounts of steam injected into the GTU on power and economic efficiency of different repowering topping schemes with partial oxidation based on use of the aircraft engine AL-31 GTU.

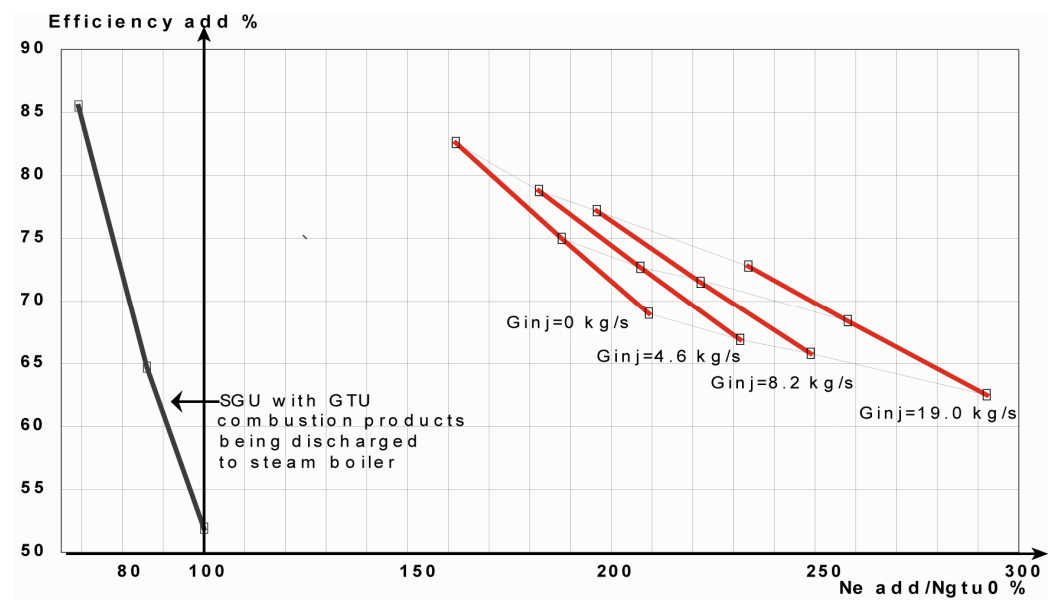

Fig. 5. Repowering by addition of AL-31 aircraft GT.

The additional power in the diagram is normalized in respect to NGTU0 -the power of the AL-31 GTU, operating in a conventional mode with one combustion chamber.

For comparison purposes the above diagrams show the indices of the scheme with the combustion products of the same aircraft GTU being discharged to the STU boiler.

\subsubsection{Results of feasibility study analysis}

Analysis made by OIVTRAN jointly with Mosenergoproyekt Power-Plant Design Institute reveals that the existing building of power plants may at best accommodate only one gas- 
turbine unit per steam-turbine plant. No acceptable technical solutions could be found involving two, to say nothing of three, gas-turbine units; in so doing, the capacity of gas turbine proper does not appear very critical (naturally, within reasonable limits).

The cost of power generation and the efficiency of capital investment are calculated with the following preconditions:

$\Delta_{1}$ - the share of depreciation charges (from specific capital costs)

- $\quad$ standard STU $=0.07$

- $\quad$ gas-turbine topping $=0.08$

$\Delta_{2}$ - the share of maintenance repair deduction (from depreciation charges) $=0.2$

$\Delta_{3}$ - the share of wage deduction (from specific capital cost) $=0.01$

c- bank interest $=0.06$

$\mathrm{z}$ - deductions from capital costs $=0.06$

$\mathrm{n}$ - number of hours of operation in year $=6000$

j- operational factor $=0.95$

The calculations were performed for three values of the relative cost of fuel: low, medium and high. The results are given graphically in Fig. 6 (relative cost of electricity).

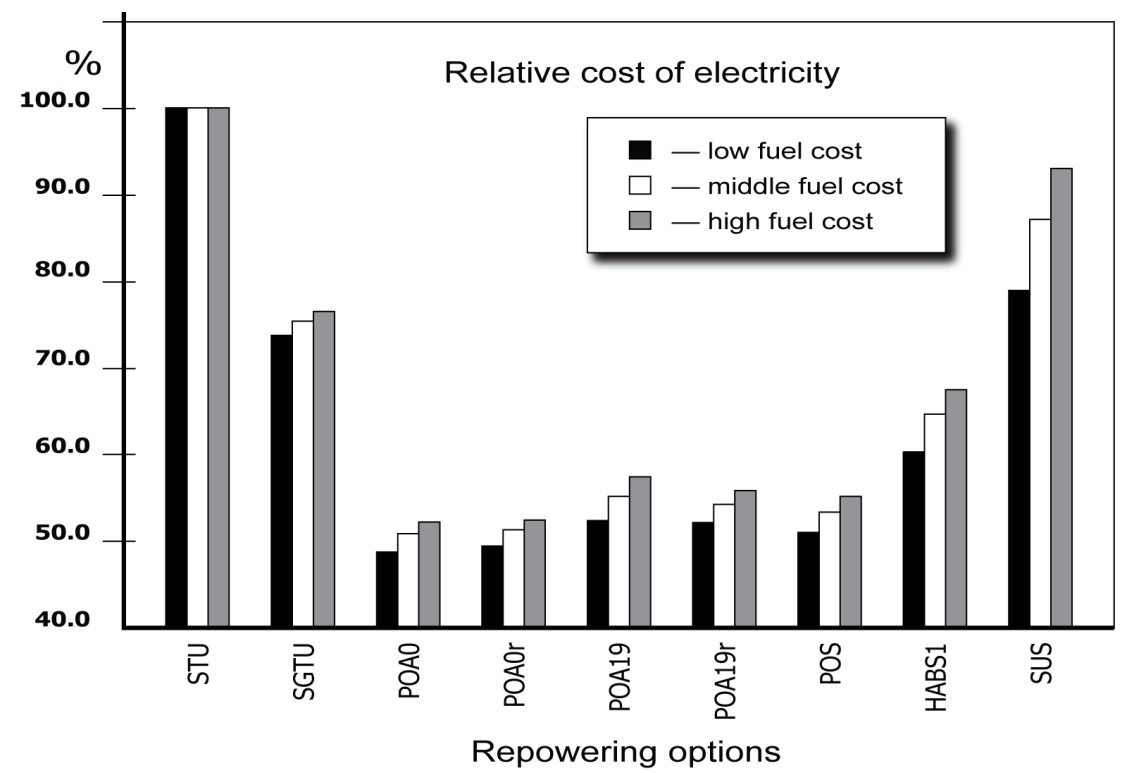

STU - conventional steam power unit, SGTU - steam-gas power unit

P0A0 - topping unit, based on aircraft engine, steam injection $=0$; without gas regeneration P0A0r - topping unit, based on aircraft engine, steam injection $=0$; with gas regeneration P0A19 - topping unit, based on aircraft engine, steam injection $=19 \mathrm{~kg} / \mathrm{c}$; without gas regeneration P0A19r - topping unit, based on aircraft engine, steam injection $=19 \mathrm{~kg} / \mathrm{c}$; with gas regeneration P0A19 - topping unit, based on stationary gas turbine engine

HABS1 - topping unit with GTU combustion products being discharged to steam boiler SUS - topping unit with GTU combined with STU in a single steam-generating circuit.

Fig. 6. Relative cost of electricity. 


\subsubsection{Conclusions}

1. Repowering the existing steam-turbine plants fired with gas and fuel oil with the aid of gas-turbine toppings is much more feasible technically and economically than the closest rival option, that of construction of advanced steam-gas plants.

2. Of all of the alternative technologies for repowering the best performance is offered by facilities with partial oxidation of fuel [5]. This technology permits of:

- $\quad$ raising the capacity of the gas-turbine unit employed by $30-50 \%$ for heavy-duty GTU and by a factor of two or two-and-a-half for aeroderivative GTU;

- reaching the efficiency of additional generation of electricity of 60 to $80 \%$.

- reducing to a minimum the NOx emission with the stack gas of steam power plants $[6,7]$;

- reducing the cost of additional generated electricity two times as compared with a steam-turbine unit.

\section{The creation of new highly efficient power production technologies}

\subsection{Environmentally friendly combined-cycle unit for cogeneration}

Steam-gas plants for electric power generation have undoubted advances compared to steam-turbine plants. When efficiency of modern condenser steam-turbine plants accounts for $38-39 \%$, the same for perspective steam-gas plants reaches $55-60 \%$. However, when speaking about cogeneration of heat and electricity, the advantages of steam-gas plant are not that evident, because the efficiency of electric power production at heat consumption and in the nominal regime become practically equal and heat production by steam-turbine unit is much more higher than in steam-gas one [9].

For the needs of characterization of the efficiency of heat producing units, the following terms are used:

- $\quad$ Fuel heat utilization factor (FHUF):

$$
\mathrm{FHUF}=\frac{N_{e}+Q_{t}}{H_{t}}
$$

here FHUF - fuel heat utilization factor, $N e$ - useful electric power (MW), Qt - district heating power (MW), $\mathrm{Ht}$ - total energy of the consumed fuel.

- Efficiency of electric power production at heat consumption regime $\eta_{\mathrm{e}}$ :

$$
\eta_{\mathrm{e}}=\frac{N_{e}}{H_{t}-\frac{Q_{t}}{\eta_{k}}}
$$

here $\eta_{e}$ - efficiency of electric power production at heat consumption regime, $\eta_{k}$ - efficiency of boiler of district heating facility.

The technology scheme of heat production steam-gas unit on the base of aviation AL-31 engine, produced by "Salut" Moscow Engineering Production Enterprise, was developed by JIHT RAS [10]. This unit has some advantages compared to traditional heating steamturbines and steam-gas units. Short description and schematic diagram are given in Fig. 7. 
Ambient air is compressed in the compressor НД (1) up to $6.3 \mathrm{~kg} / \mathrm{cm} 2$ (abs) and fed in the mixing type air cooler (3), where the processes of saturation by steam and cooling down by evaporation take place. The use of air cooler gives the opportunity to keep the air temperature at the compressor high pressure (2) outlet at the rated level of initial gasturbine engine (446 0C) and keep the normal mode of blade row operation.

Compressed air, natural gas and steam with temperature $285 \mathrm{oC}$ are fed into combustion chamber of steam-gas unit, providing the following parameters of the working fluid at the compressor common drive turbine inlet: pressure in 64 ata, temperature $1310 \mathrm{oC}$, at excess air factor $a=1,12$. Steam is used for the cooling of turbine group elements, thus the temperature of cooling agent can be increased over the design value for the original gas-turbine unit at keeping the temperature of blade row metal temperature below the design value.

At the outlet from the group of driving turbines, the steam-gas mixture is fed into the regenerative heat exchanger (6) where the generation and superheat of the injected steam take place together with the heating of network water for cogeneration purposes.

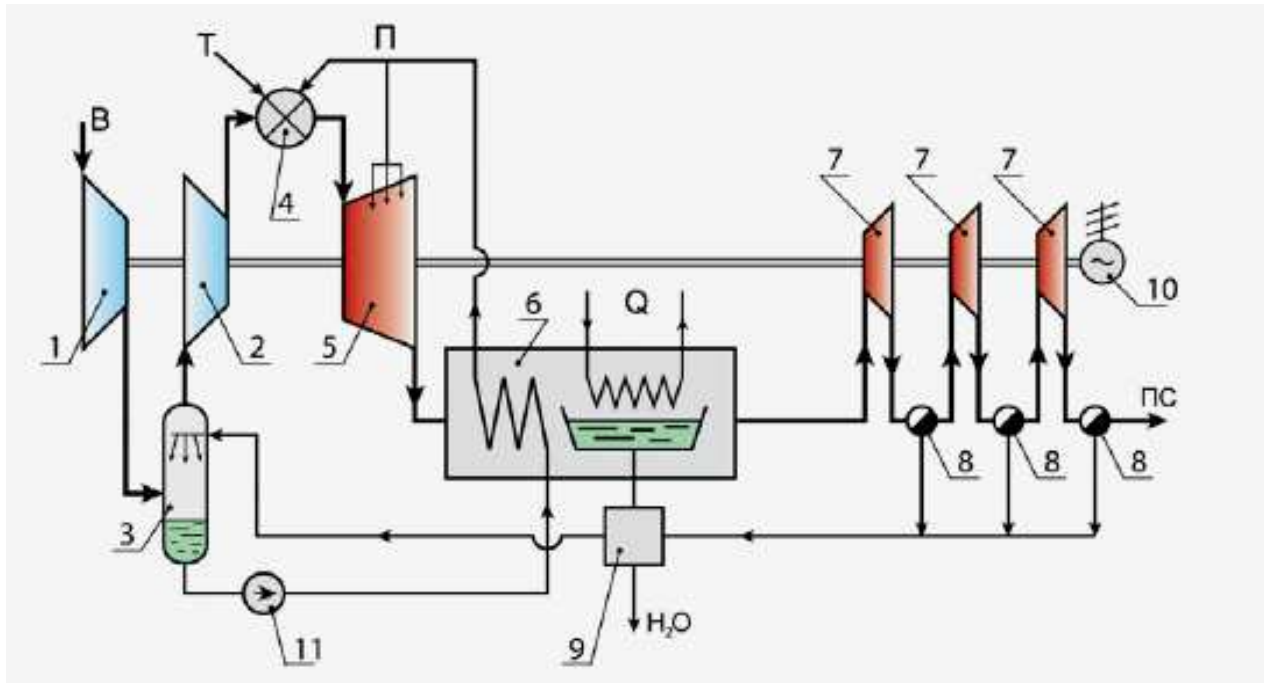

1 - low-pressure compressor, 2 - high-pressure compressor, 3 - air cooler, 4 - combustion chamber, 5 gas turbine, 6 - heat exchanger, 7 - expander stage, 8 - drift eliminator, 9 - purifier, 10 - electric generator, 11 - feed pump, B - air, T - natural gas, $\Pi$ - steam, $\Pi C$ - products of combustion, $\mathrm{Q}$ - district heating system water

Fig. 7. The scheme of steam-gas unit for co-production of heat and electricity.

The main peculiarity of the proposed scheme is higher pressure in the heat exchanger (3.05 $\mathrm{kg} / \mathrm{cm} 2$ (abs)) which increases partial pressure of water vapor and gives the opportunity to condensate it at the temperature level that fits the requirements of standard district heating system for network water.

After the heat exchanger (6) steam-gas mixture is expanded up to ambient pressure in the gas expansion stage (7) with the generation of useful work and additional water due to condensation. The additional water is captured by drift eliminator (8). 
Together with the main flow of condensate from the heat exchanger (6) this water is fed to the purifier (9) and after that is fed to the air cooler (3) and after that to the steam generation and steam superheat in the heat exchanger (6). The excess water condensed from the combustion products can be used for any purpose.

The steam-gas unit based on the described scheme and using the equipment of АЛ-31 gasturbine unit will have the following features (at nominal regime):

1. Useful electric power - 62.4 MW,

2. Useful thermal power-77.8 MW,

3. Efficiency at heat consumption $-115.9 \%$.

4. FHUF - $103.3 \%$,

5. Air flow $-52.4 \mathrm{~kg} / \mathrm{s}$,

6. Condensate excess $-8.6 \mathrm{t} / \mathrm{h}$.

The values of efficiency and FHUF exceed $100 \%$, which is not a paradox and resulting from the term "the fuel lower calorific value", where the heat of condensation of steam generated at hydrogen fuel oxidation is not taken into account.

Since the products of combustion in the expansion machine are cooled below the dew point, the heat of condensation is transformed in work. The main parameters comparison for alternative heating units is given in Table 4 .

\begin{tabular}{|c|c|c|c|c|}
\hline \multirow{2}{*}{ Characteristics } & \multicolumn{4}{|c|}{ Type of the cogeneration system } \\
\cline { 2 - 5 } & Steam-turbine & \multicolumn{3}{|c|}{ Combimed steam-gas plant } \\
\cline { 2 - 5 } & T-250/300-240 & SGU 450T & SGU 230 & Plant on fig.7 \\
\hline Net electric power, MW & 231,9 & 433,8 & 213,6 & 62,4 \\
\hline Net heating power, MW & 384,0 & 410,5 & 160,5 & 77,8 \\
\hline Fuel consumption, MJ/s & 726,8 & 1033,1 & 460,2 & 135,7 \\
\hline FHUF & 84,7 & 72,2 & 73,3 & 103,3 \\
\hline Efficiency at heat consumption & 71,9 & 72,2 & 73,3 & 115,9 \\
\hline
\end{tabular}

Table 4 . The main parameters comparison for alternative heating units.

\subsubsection{The main backgrounds of equipment selection and of the calculation of principle scheme of the unit}

The main principle of the prototype selection for separate parts of the steam-gas unit and of the further calculation of thermal flow scheme is the priority of domestic aggregates and assemblies both, existing or under implementation by power engineering, i.e. the equipment without substantial difficulties concerning design and manufacture. As the main aggregate of the steam-gas unit of turbo -compressor group, the gas generator of АЛ-31 gas-turbine unit, produced by NPO "Saturn" is proposed.

The preliminary analysis of the proposed scheme shows the necessity to make the following changes in the design of the original gas-turbine unit:

1. the nominal air flow should be decreased from $63.5 \mathrm{~kg} / \mathrm{s}$ down to $52.4 \mathrm{~kg} / \mathrm{s}$ according to the requirement of keeping the maximal mechanical stress in the blade group of compressors within the design value; 
2. the low pressure compressor must be added by a group of stages to increase the total compression rate;

3. the cooling air in the cooling system of gas turbine must be replaced by steam without any change of the design. In this case the value of steam flow rate in the cooling system is defined by initial steam pressure and by hydraulic resistance of the cooling system. Numerous literature data prove that at the transition to steam cooling, the temperature of the working fluid can be increased on $90-110{ }^{\circ} \mathrm{C}$ at the same temperature of blade group metal. In the proposed scheme, the initial temperature of the working fluid is $1310^{\circ} \mathrm{C}$, being in $53{ }^{\circ} \mathrm{C}$ higher than the design value for АЛ-31 unit. In this case, the temperature of metal in the most loaded parts of steam-gas units is lower than the design value, thus increasing the unit operation reliability.

The preliminary estimations done in cooperation with the group of designers of NPO "Saturn" showed that the air-gas channel is able to let through the design flow of working fluid; the power turbine must be redesigned due to the increase of last stage blades length. The use of power turbine from another NPO "Saturn" product could be the alternative.

The designs of mixing air cooler and of heat exchangers are based on the commercial elements and have been elaborated by the specialists of NPO "Raduga".

At the calculations within the design of the expansion machine, the average aerodynamics of low-pressure cylinder stage of condensing steam turbines was taken into account with respect to the decrease of air-gas channel efficiency due to drop precipitation.

The general principle used at calculations and design is the creation of the unit consisting of restrained number of commercial parts with the opportunity of transportation by standard railroad platform. The necessity to use intensified heat exchanges, because of this, positively influenced the mass and the cost of the equipment but decreased thermal efficiency.

\section{Power and Chemical Complex for co-production of electricity and synthetic liquid fuel}

Power and Chemical Complex for co-production of electricity and synthetic liquid fuels (methanol, dimethyl ether, gasoline) - a promising way for saving of fuel resources.

Up to now, the progress in any branch is connected with the upgrade of one product type production technology. The thematic example for this is the progress in power production connected with the modernization of steam-gas binary cycle utilizing natural gas as a fuel. Modern steam-gas units have $55 \%$ efficiency with the perspective of its growth up to $60 \%$. The upgrade is taking place both due to technological scheme optimization and by the increase of actuating medium parameters at the inlet of gas turbine.

However, this way practically has reached the limit and though the further increase of working fluid parameters can increase the efficiency, the cost of produced energy most likely cannot be decreased due to investment cost growth. To our opinion the better perspective in the utilization of fossil fuels and the natural gas first of all can be obtained by the creation of power and chemical complexes with technological scheme optimized for the mass of several end products [11,12].

Certainly, it is not possible to say that in all technologies only one end product have been manufactured up to now. The production of several types of products exists but in the way 
of by-product production with the main mono-product being the target for the technological scheme. The basic principle for the creation of power and chemical complex technological scheme is solving several target problems by one technological process producing synergy effect by the combination of several technologies.

With this, the positive feasibility effect is obtained by the following:

- high economy efficiency due to the synergy effect induced by integration of production of several type of mass products,

- the use of the most up-to-date technologies both newly developed or taken from various branches of industry,

- multiple decrease of ecological damage to the regions of the unit sites due to decrease or in some cases total elimination of harmful emission,

- involvement, together with traditional energy sources, such primary energy resources as low- natural gas, oil gases and coal-mine methane,

- the opportunity to create feasible energy-dependent medium and small capacity plants in case of need.

The essence of the considered energy and technology complexes is the partial oxidation reaction of the initial hydrocarbons with production of energy and synthesis gas, which includes of $\mathrm{CO}$ and $\mathrm{H}_{2}$. The released heat can be used for power production. The $\mathrm{CO} / \mathrm{H}_{2}$ ratio in the synthesis gas and the presence of $\mathrm{H}_{2} \mathrm{O}, \mathrm{CO}_{2}, \mathrm{~N}_{2}$ depends on the initial hydrocarbon composition and on the technology of partial oxidation reaction.

Thermodynamic analysis and the study of kinetics of the process resulting in synthesis gas origination show that the process occurs efficiently and quickly at relatively high temperatures without catalyst. The mathematical model developed in IVTAN helps to select the optimal parameters of the process, initial component composition and determine the time process duration needed for the reaction of partial oxidation .

The first synthesis gas generator has been created in IVTAN on the base of upgraded diesel engine, where the cylinder is a unique device combining the features of compressor, high temperature chemical reactor and thermal energy to mechanical work transformer $[11,13]$.

Fig. 8 shows the appearance of Д- 245 of $80 \mathrm{~kW}$ diesel-based synthesis gas generator.

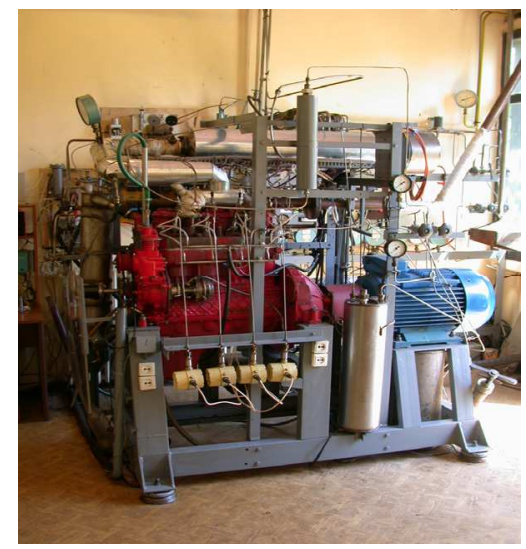

Fig. 8. Д-245 diesel-based synthesis gas generator. 
The generator utilizes natural gas or natural gas with butane-propane thus imitating the possible compositions of oil gases. The air is used as oxidant. Excess air factor, necessary for synthesis gas production accounts for 0,4-0,6 which is absolutely inappropriate for the regular diesel operation. The transformation of diesel to synthesis gas generator demanded additional efforts, which were successful.

The synthesis gas generator in combination with catalytic reactor of methanol synthesis (Fig. 9) received the name "Sintop-300" plant. The plant capacity is $\sim 800 \mathrm{l}$ of methanol per day. The plant was involved in the wide range of experimental investigations.

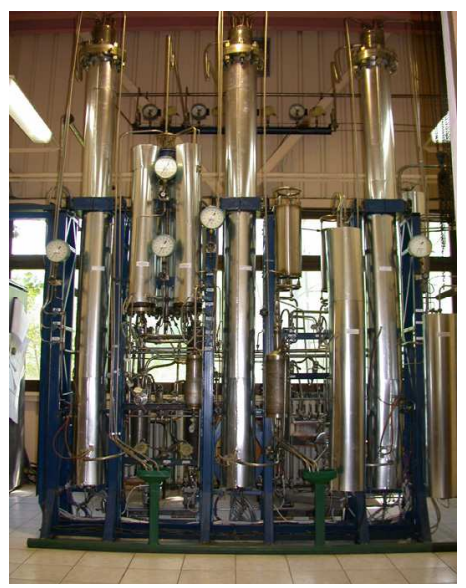

Fig. 9. "Sintop-300" plant.

The following are the main outcomes of these investigations:

- the opportunity to organize non-catalytic conversion of natural hydrocarbon gases by partial oxidation by air at the parameters that are technically achievable,

- the possibility for efficient catalytic methanol synthesis from synthesis gas ballasted by air nitrogen,

- the possibility to create feasible energy-dependent commercial low and middle capacity units for the conversion of gaseous hydrocarbons to liquid chemical products.

It is worth mentioning that the modified diesel based synthetic gas generator is able to operate with low-pressure gases, such as off-balance or worked-out gas fields, coal bed methane, oil gases. With the use of the obtained results in 2008, the pilot plant was designed with capacity of 12000 tons of methanol per year. The main equipment was selected or partly manufactured, namely synthesis gas generator (Fig. 10), compressor, heat exchangers etc. The generator was based on 16-piston H26/26 diesel engine with net capacity $2000 \mathrm{KW}$, produced by Kolomna mechanical engineering holding.

The further development of energy and technology complexes is connected with the development of continuous-flow generator variant, allowing the use of gas-turbine and thus to increase substantially the unit capacity and start the production of the units with capacities compared with modern level of power plants. The process flow sheet of such a perspective energy and technology complex is presented in Fig.11. 


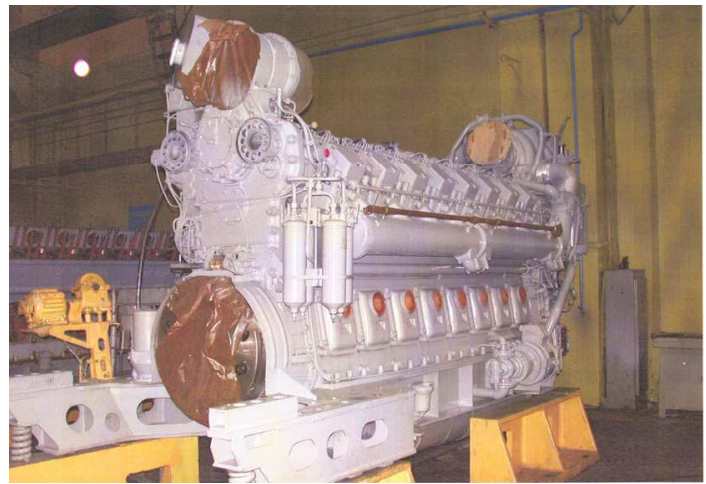

Fig. 10. Synthesis gas generator.

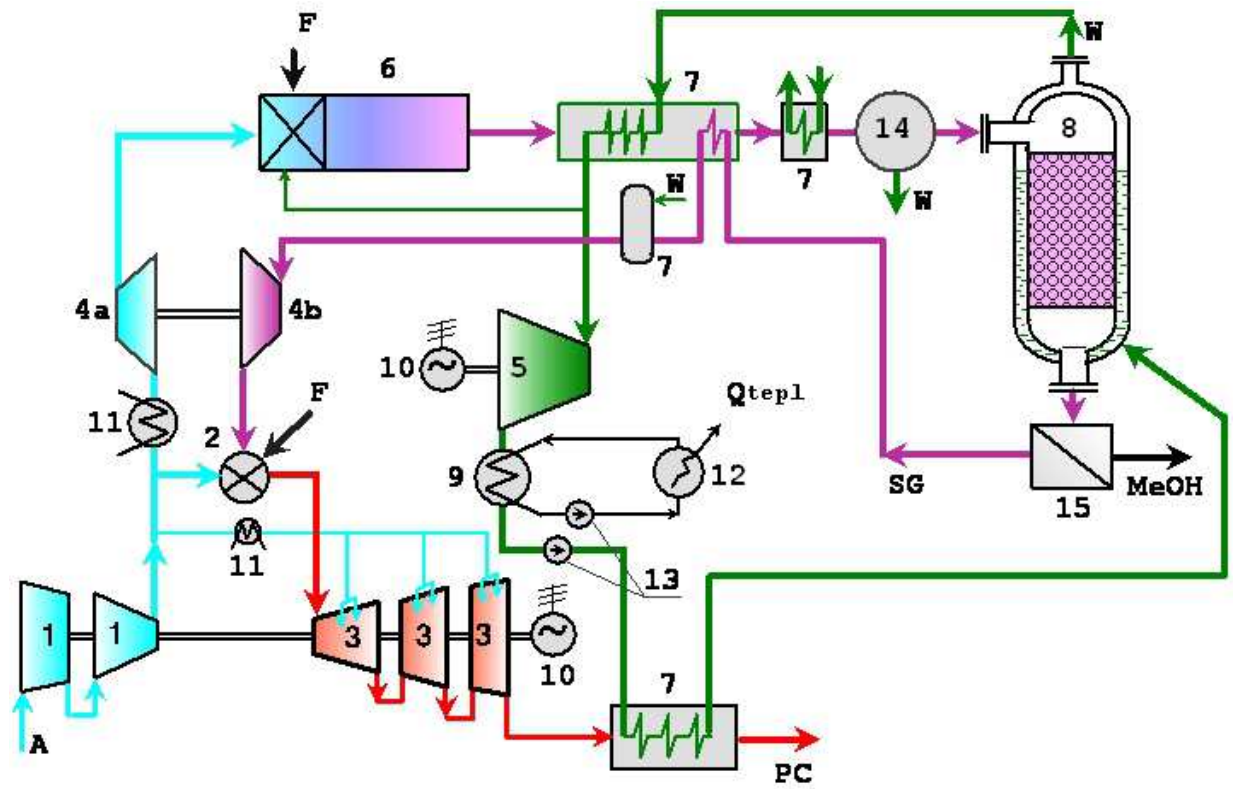

1 - compressor, 2 - the gas turbine combustor, 3 - gas turbine, $4 \mathrm{a}$ - air buster compressor, $4 \mathrm{~b}$ - turbodetander, 5 - steam turbine, 6 - partial oxidation chamber, 7- syngas cooler and waste-heat boiler, 8synthesis $\mathrm{CH}_{3} \mathrm{OH}$ reactor, 9 - steam condenser, 10 - electric generator, 11 - air cooler, 12 - water cooling tower, 14 - separator, 15 - product separator.

Fig. 11. Combined utilization of natural gas with the use of steam-gas turbine with the production of methanol, thermal and electric energy.

Conversion АЛ-31 aircraft engine is used as power unit. Compressed air after the compressor of the gas-turbine unit is additional compressed by compressor of the turboexpander to $5.0 \mathrm{MPa}$ and is fed to synthesis gas generator to where all the natural gas consumed by the plant is fed. The partial oxidation of natural gas is conducted in synthesis gas generator at temperatures $1200-1300{ }^{\circ} \mathrm{C}$. 
The obtained synthesis gas is cooled with the heat regeneration in power production cycle and fed in single-pass catalytic methanol synthesis reactor, where about $50-60 \%$ is converted to methanol.

The remaining gas, ballasted by nitrogen is expended in turbine of the turbo-expander and fed to the combustion chamber of gas-turbine unit.

Let us name all the advantages of the proposed scheme:

- compressed air, being the working fluid of the gas-turbine unit, is fed to the synthesis gas generator without substantial energy consumption,

- the single-pass methanol synthesis reactor with low degree of synthesis gas conversion is used, because the remaining gas is the fuel for gas-turbine unit,

- there are no energy losses at the recuperation of compressed gas energy after the methanol synthesis reactor,

- the power producing unit becomes automatically ecologically clean because the reburning of low calorific gas takes place in the gas-turbine unit combustion chamber practically without origination of toxic nitrogen oxides, both "thermal" (Zeldovich mechanism) or «prom + NOx).

The cogeneration of two products gives the opportunity to decrease considerably the cost of electricity even compared to the existing steam-gas plants. Fig. 12 shows the comparison results of relative feasibility indicators of various power plants, where the reference is the cost of electricity generated by $300 \mathrm{MW}$ steam-turbine power plant.

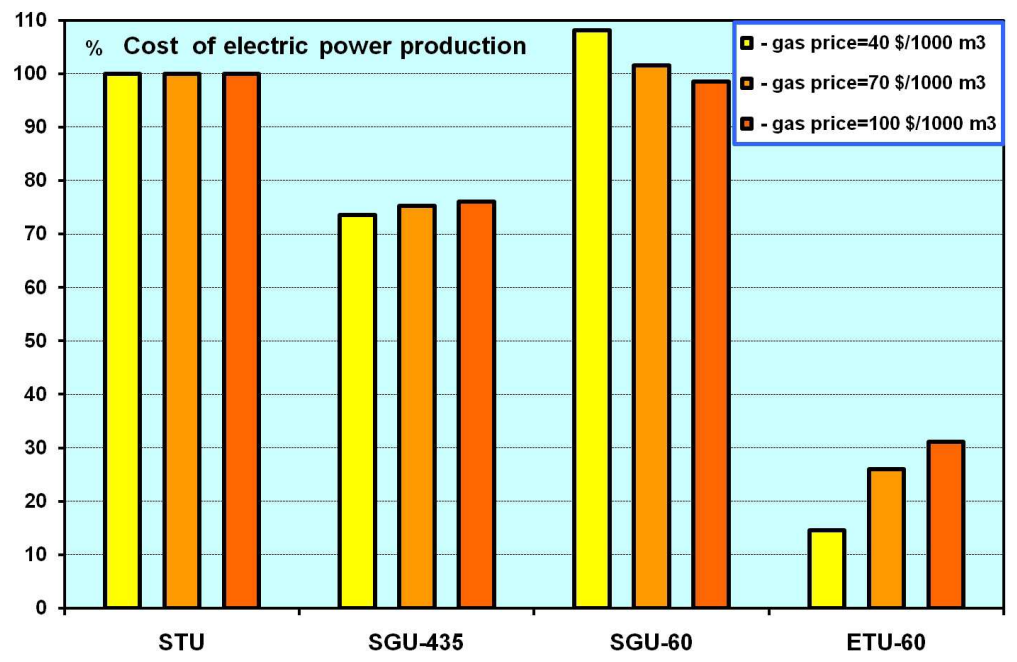

Fig. 12. The comparison results of relative feasibility indicators of various power plants.

The comparison of the cost of electricity after deduction of methanol cost of production at modern big enterprise is conducted for four alternatives at the variation of natural gas cost:

- $\quad$ steam-turbine power unit for supercritical steam parameters with $300 \mathrm{MW}$ capacity STU,

- $\quad$ binary cycle steam-gas unit with capacity 435 MW (SGU 435), 
- $60 \mathrm{MW}$ binary cycle steam-gas unit (SGU 60),

- $62 \mathrm{MW}(\mathrm{e})$ power and chemical complex (ETU-60).

The creation of such energy and technology complexes demands the salvation of a range of problems, where in the first place, are fine-tuning of natural gas conversion in the continuous flow reactor and the turbine operation with the use of synthesis gas ballasted by nitrogen. In order to solve these problems together with the range of other tasks, experimental-industrial unit with 1.2 MW gas turbine was created in accordance with state contract financed by the Ministry of Education and Science.

The unit includes practically all important elements of the scheme of energy and technology complex. The appearance of the unit under creation is presented in Fig.13.

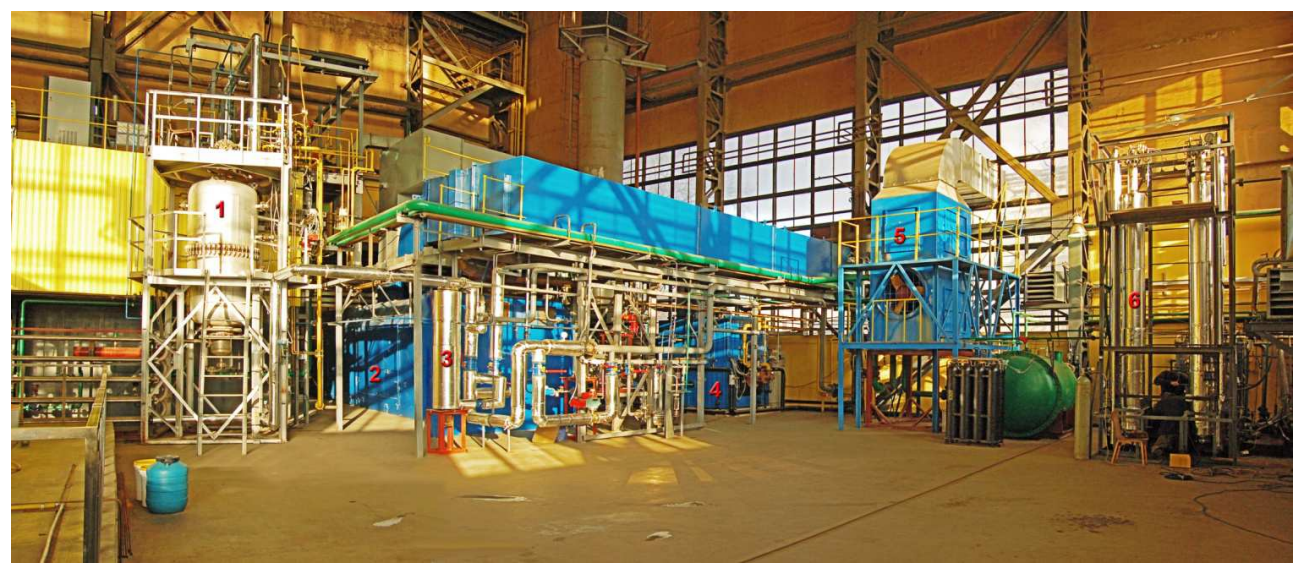

1 - The synthesis gas generator by partial gas oxidation with syngas cooler, 2 - gas turbine, 3- soot filter, 4 - water heating boiler, 5 - water cooling tower, 6 - block of methanol synthesis.

Fig. 13. Experimental-industrial unit with 1.2 MW gas turbine.

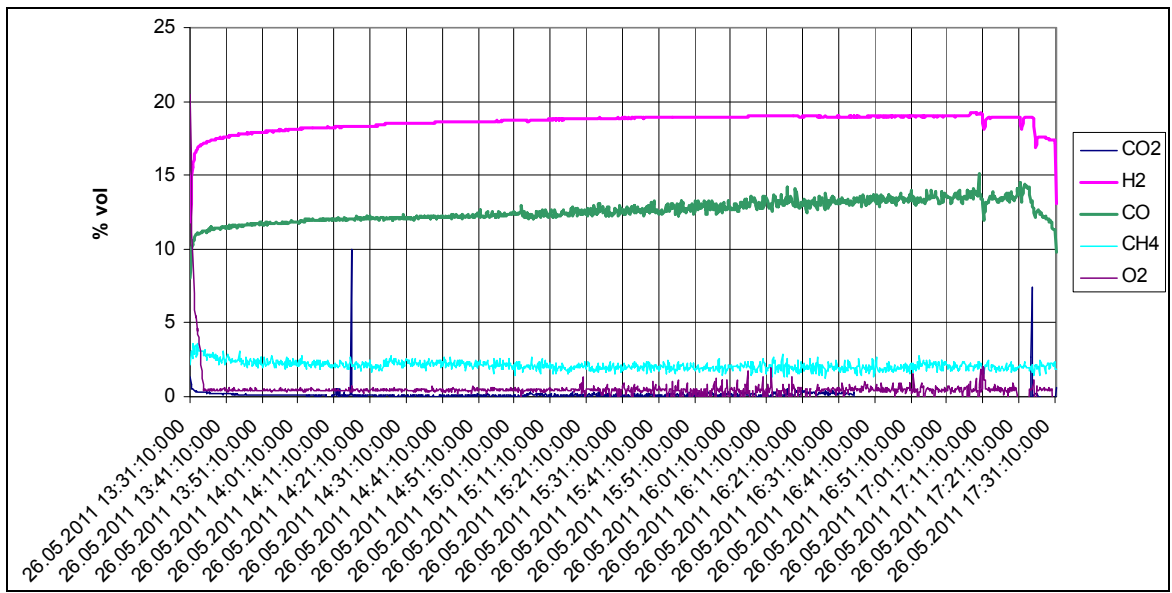

Fig. 14. Experimental data on the generating gas composition in $\%$ vol. $\left(\mathrm{N}_{2}\right.$ and $\mathrm{H}_{2} \mathrm{O}$-is rest). 
The industrial energy and technology complex could be created, for example, on the base of 20 MW gas-turbine unit produced by "Salut" Moscow Engineering Production Enterprise. Using two of such gas-turbine units, the energy and technology complex can have electric capacity of $50-60 \mathrm{MW}$ and produce up to 150000 tons of methanol per year. The cost of electricity generated could be 2.5 - 3 times lower than at perspective high-capacity steamgas unit and the exhaust gases practically free from toxic NO.

\section{Total conclusions}

1. The new approaches described above do not limit all the possibilities for the upgrade of the existing and for the creation of new power production technologies that increase the efficiency of natural gas utilization and decrease the harmful emission to the environment.

2. The implementation of relatively simple technical solutions in upgrade of existing power production technologies often give bigger saving rate per the investment unit, than at the creation of new traditional power production technologies.

3. The creation of energy-technology complexes of co-generation of energy, synthetic liquid fuel and other valuable accompanying products of mass demand is the perspective way for rational use of the fossil fuels (natural gas, coal, shale).

\section{Acronyms and abbreviations}

GTU - Gas Turbine Unit;

SGU - Combined-cycle Steam-Gas Turbine Units;

STU - Steam Turbine Unit;

$\mathrm{Ne}$ - electric power, MW;

$\boldsymbol{H}_{T}$ - energy of the fuel combusted, MW;

$Q_{T}$ - thermal capacity of the boiler, MW;

$\eta_{b}$-boiler efficiency;

$\eta_{e}$ - electric power production efficiency at heat combustion;

Ne add, MW- additional useful power output of the steam-gas unit after repowering;

$\mathrm{Eff}_{\mathrm{ad}}$ - thermal efficiency of Generation Additional Electric Power after repowering;

$\mathrm{Ne}$ - useful electric power (MW);

$Q t$ - district heating power (MW);

$\mathrm{H} t$ - total energy of the consumed fuel.

FHUF - fuel heat utilization factor;

$N_{S G U}$ and $N_{\text {STU }}$ are the useful power output of the repowered and original unit, respectively, operated at nominal rate;

$\Sigma g_{i}{ }^{*} Q_{i S G U}$ and $\Sigma g_{i}{ }^{*} Q_{i S T u}$ are the energy of all kinds of fuel burnt in the repowered and original units, respectively, at nominal rate;

\section{References}

[1] V. Bushuev, A. Troitskii “The Energy Strategy of Russia until 2020 and Real Life. What Is Next?" Thermal Engineering Vol.54, Number 1, January 2007, pp 1-7.

[2] V.M. Maslennikov, V.Ja. Shterenberg, "Method of the heat transforming into useful mechanical work in the cycle with multistage combustion", Patent of Russia 1809141 Apr., 1991/ 
[3] V.M. Maslennikov (USSR), R.G. Smithson (USA) et al. “Steam-and-Gas Units with Fuel Gasification within the Cycle and Ecological Problems of Power Engineering" Battele Memorial Institute, USA, 1992.

[4] V.M. Maslennikov, V.Ja. Shterenberg, "Environmentally Clean Efficient Steam - Gas Units for Repowering of Existing Power Plants", "Energeticheskoe Stroitel'stvo", Moscow, 8, 1992/

[5] V.M. Maslennikov, V.Ja. Shterenberg "Advanced gas turbine system utilizing partial oxidation technology for ecologically clean power generation", International Journal of Low-Carbon Technologies, Jan., 2011.

[6] S. Daw, K. Charkavathy, J. Pihl, J. Conkin (Oak Ridge National Laboratory) "The Theoretical Potential of Thermochemical Exhaust Heat Recuperational for Improving the Fuel Efficiency of Internal Combustion Engines", Presentation to the Chicago Section of AICHE, may 17.2011/

[7] P. Childs "Chemical looping combustion for high efficiency and carbon capture", Gas Turbine World, May-June 2011, pp 24-27.

[8] V. de Biasi "1.8:1 steam-to-fuel ratio reduces NOx output of LM 2500 to 5 ppm", Gas Turbine World, May-June 2011, pp 12-17.

[9] V. Dobrokhotov, Yu. Zeigarnik "Cogeneration: Problems and Possibilities of Realization under Present Conditions" Thermal Engineering Vol.54, Number 1, January 2007, pp 8-9.

[10] V.M. Maslennikov, Yu.A. Vyskubenko, E.A. Tsalko, V.Ya. Shterenberg. E.G. Shadek. "Heat generation in steam-gas cycle and steam-gas unit for its implementation", RF Patent №217942 F01K 26/06 of 25.04.2001.

[11] V.M. Batenin, V.M. Maslennikov, L.S. Tolchinsky “Technology of combined production of electricity and liquid synthetic fuel with the use of gas-turbine and steam-gas units", RF Patent №2250872, 27.04.2005.

[12] V.M. Batenin, V.M. Maslennikov, Yu.A. Vyskubenko "Technology for the complex use of solid fuel in power production units with cogeneration of energy and sideline products", RF Patent №2364737, 20.08.2009 г.

[13] I. I. Lishchiner, O. V. Malova, A. L. Tarasov, V. M. Maslennikov, Yu. A. Vyskubenko, L. S. Tolchinskii, Yu. L. Dolinskii "Synthesizing Methanol from Nitrogen-Ballasted Syngas” . ISSN 2070-0504 Catalysis in Industry, 2010, vol.2, No.4, pp. 368-373. 


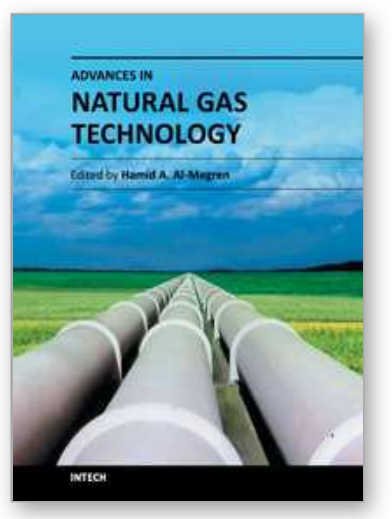

\author{
Advances in Natural Gas Technology \\ Edited by Dr. Hamid Al-Megren
}

ISBN 978-953-51-0507-7

Hard cover, 542 pages

Publisher InTech

Published online 11, April, 2012

Published in print edition April, 2012

Natural gas is a vital component of the world's supply of energy and an important source of many bulk chemicals and speciality chemicals. It is one of the cleanest, safest, and most useful of all energy sources, and helps to meet the world's rising demand for cleaner energy into the future. However, exploring, producing and bringing gas to the user or converting gas into desired chemicals is a systematical engineering project, and every step requires thorough understanding of gas and the surrounding environment. Any advances in the process link could make a step change in gas industry. There have been increasing efforts in gas industry in recent years. With state-of-the-art contributions by leading experts in the field, this book addressed the technology advances in natural gas industry.

\title{
How to reference
}

In order to correctly reference this scholarly work, feel free to copy and paste the following:

Victor M. Maslennikov, Vyacheslav M. Batenin, Yury A. Vyskubenko and Victor Ja. Shterenberg (2012). Innovative Technologies for Natural Gas Utilization in Power Generation, Advances in Natural Gas Technology, Dr. Hamid Al-Megren (Ed.), ISBN: 978-953-51-0507-7, InTech, Available from: http://www.intechopen.com/books/advances-in-natural-gas-technology/innovative-technologies-for-naturalgas-utilization-in-power-generation

\section{INTECH}

open science | open minds

\author{
InTech Europe \\ University Campus STeP Ri \\ Slavka Krautzeka 83/A \\ 51000 Rijeka, Croatia \\ Phone: +385 (51) 770447 \\ Fax: +385 (51) 686166 \\ www.intechopen.com
}

\author{
InTech China \\ Unit 405, Office Block, Hotel Equatorial Shanghai \\ No.65, Yan An Road (West), Shanghai, 200040, China \\ 中国上海市延安西路65号上海国际贵都大饭店办公楼405单元 \\ Phone: +86-21-62489820 \\ Fax: $+86-21-62489821$
}


(C) 2012 The Author(s). Licensee IntechOpen. This is an open access article distributed under the terms of the Creative Commons Attribution 3.0 License, which permits unrestricted use, distribution, and reproduction in any medium, provided the original work is properly cited. 